\title{
Plant soil feedback strength in relation to large-scale plant rarity and phylogenetic relatedness
}

\author{
Anne Kempel, ${ }^{1}$ Abiel Rindisbacher, Markus Fischer, and Eric Allan \\ Institute of Plant Sciences, Altenbergrain 21, 3013 Bern, Switzerland
}

\begin{abstract}
Understanding why some species are rare while others are common remains a central and fascinating question in ecology. Recently, interactions with soil organisms have been shown to affect local abundances of plant species within communities, however, it is not known whether they might also drive patterns of rarity at large scales. Further, little is known about the specificity of soilfeedback effects, and whether closely related plants share more soil pathogens than more distantly related plants. In a multi-species soil-feedback experiment (using 19 species) we tested whether regionally and locally rare species differed in their response to soil biota. Regional rarity was measured using range size or IUCN status and local rarity by typical abundance within an area. All species were grown on soils trained by a variety of regionally and locally rare and common species, which also varied in their degree of relatedness to the target. We found that, in general, regionally rare species suffered more than twice as much from soil biota than regionally common species. Soil cultured by regionally rare species also had a more negative effect on subsequent plant growth, suggesting they may have also accumulated more pathogens. Local rarity did not predict feedback strength. Further, soil trained by closely related plants had a more negative effect on growth than soil trained by distant relatives, which indicates a phylogenetic signal in the host range of soil biota. We conclude that soil biota may well contribute to plant rarity at large spatial scales, which offers a novel explanation for plant rarity and commonness. Moreover, our results show that phylogenetic relatedness between plants was a good predictor of the likelihood that two plant species interacted negatively via soil biota, which might mean that soil pathogens could prevent the coexistence of closely related plants and could drive patterns of phylogenetic overdispersion. Our results suggest that soil pathogens could restrict the ability of rare species to shift their ranges and might need to be considered by conservation biologists seeking to protect populations of rare plants.
\end{abstract}

Key words: host range; local abundance; phylogenetic distance; plant commonness; regional rarity; soil pathogens; soil-feedback; spill-over.

\section{INTRODUCTION}

Many hypotheses address why some species are rare with low abundances, small ranges and declining populations while others are common, range widely and have stable or increasing populations (Gaston 1994). Most theories attempting to explain the commonness of species focus on niche breadth (Brown 1984, Slatyer et al. 2013) or niche position (Hanski et al. 1993) and mostly consider abiotic niches (Boulangeat et al. 2012, Slatyer et al. 2013). However, biotic interactions, such as disease, predation or mutualisms, can also determine niches (Petermann et al. 2008). Increased sensitivity to herbivores and disease, or a lack of mutualists, might therefore explain the low abundances and small range sizes of many species.

By releasing exudates and other products from their roots, plants culture a species-specific soil community in their rhizosphere, which can affect the subsequent growth and performance of the same, or other, species (Kulmatiski et al. 2008, Bever et al. 2015). Locally rare plant species can suffer more from specialist soil pathogens meaning they grow worse in their own soil than in heterospecific soil (Fig. 1A,

Manuscript received 8 September 2017; revised 18 December 2017; accepted 20 December 2017. Corresponding Editor: Jacob Weiner.

${ }^{1}$ E-mail: anne.kempel@ips.unibe.ch
Klironomos 2002, Mangan et al. 2010, MacDougall et al. 2011, McCarthy-Neumann and Ibáñez 2012, Rutten et al. 2016, but see Reinhart 2012, Maron et al. 2016). However, local abundance is only one aspect of rarity. Even more important from a conservation perspective might be large scale rarity. This is not necessarily related to local rarity as species can have restricted ranges but be locally common, or can have large range sizes but be locally rare (Rabinowitz 1981).

The role of soil organisms in determing rarity at large scales has so far been addressed only in the context of plant invasions, where a low susceptibility to soil enemies (Engelkes et al. 2008) and/or the ability to take advantage of new mutualists (Callaway et al. 2004) may allow plant species to expand their ranges. Similar mechanisms might operate for native species: a low susceptibility to generalist pathogens, and/or a high ability to take advantage of generalist mutualists, might allow species to spread and become regionally common, whereas a high susceptibility to generalist pathogens could prevent spread into new habitats, resulting in restricted ranges (Fig. 1A). Generalist pathogens or mutualists are more likely to determine range size because highly specialist (species specific) pathogens can only affect local rarity (abundance), as they cannot restrict spread into new habitats given that they are missing from areas uncolonised by their hosts (Turnbull et al. 2010). However, highly generalist pathogens, or pathogens which can attack a 
A

\begin{tabular}{|c|c|c|}
\hline & Rare (subordinate) & Common (dominant) \\
\hline 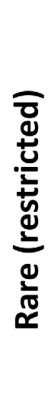 & $\begin{array}{l}\text { Suffers from all pathogens } \\
\text { and/or } \\
\text { benefits little from all mutualists } \\
\text { Specialist pathogens (and/or lack of mutualists) cause } \\
\text { lack of mutualists) prevent spread into new habitats }\end{array}$ & $\begin{array}{l}\text { Suffers from generalist pathogens but less } \\
\text { from specialists } \\
\text { and/or benefits from specialist mutualists but } \\
\text { less from generalists } \\
\text { More generalist pathogens (or lack of specialist } \\
\text { mutualists) prevent spread into new habitats }\end{array}$ \\
\hline 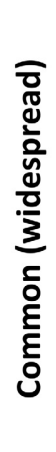 & $\begin{array}{l}\text { Suffers from specialist pathogens but not generalists } \\
\text { and/ or benefits from generalist mutualists but less } \\
\text { from specialists } \\
\text { Specialist pathogens cause strong NFD within habitat; } \\
\text { relatively low generalist pathogen impact (or large } \\
\text { benefit from generalist mutualists) allows spread into } \\
\text { new habitats }\end{array}$ & $\begin{array}{l}\text { Not strongly affected by all pathogens } \\
\text { and/ or } \\
\text { benefits strongly from mutualists } \\
\text { Low pathogen impact (or large benefit from } \\
\text { mutualists) leads to low NFD within habitat and } \\
\text { allows spread into new habitats }\end{array}$ \\
\hline
\end{tabular}

B
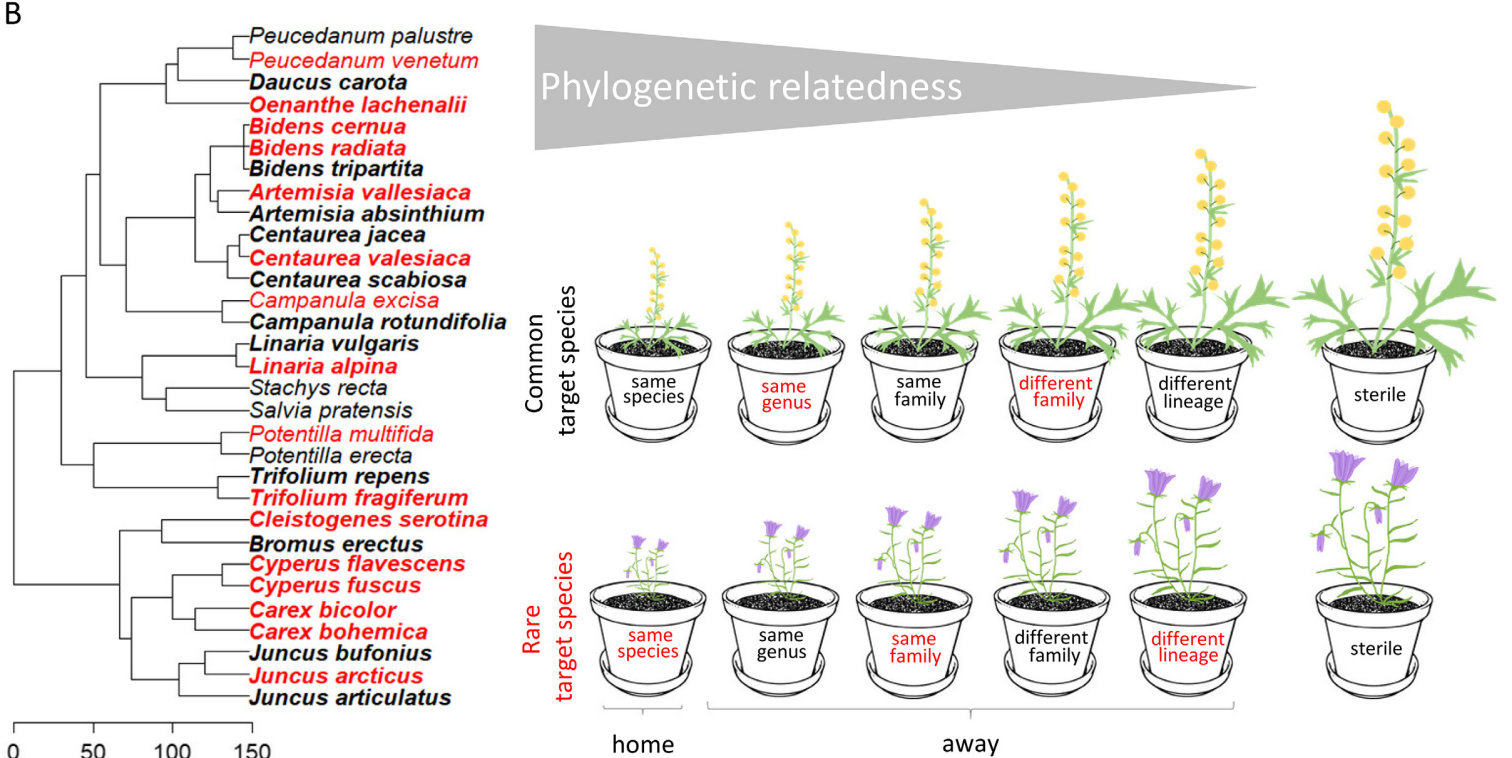

home

away

Million years before present

FIG. 1. (A) Framework explaining how interactions with specialist and generalist pathogens and mutualists could explain plant rarity at a local and regional scale. While species specific pathogens (and/or the lack of mutualists) might cause negative frequency dependence (NFD) within a habitat and cause local rarity, generalist or only moderately specialist pathogens (or lack of mutualists) prevent the spread into new habitats which results in regional plant rarity. (B) Design of the experiment and a conceptual illustration of the hypothesis that soil feedback strength becomes more negative with increasing phylogenetic relatedness (different sizes of depicted plants). Twenty-four target plant species (bold species names), of which 12 were regionally common (colored in black) and 12 regionally rare and endangered (colored in red) and which differed in their local rarity (Appendix S1: Table S1), were grown in sterile soil or in soil trained by plants (soil species) that differed in their regional and local rarity and that were more or less closely related to the target species. Each target species was grown on soil trained by regionally and locally rare and soil trained by regionally and locally common plant species. 
number of closely related hosts (i.e., moderately specialist pathogens), could restrict the range size of their host plants.

While there is little theoretical and empirical evidence for why rare species should fail to take advantage of generalist mutualists, there are several reasons why they might be more susceptibile to generalist, or moderately specialist, soil pathogens. First, rare and declining species might have reduced genetic diversity (Spielman et al. 2004), making them more susceptible to disease. Secondly, rare species might encounter fewer pathogens within their habitats because they are less apparent (Feeny 1976) or because they are isolated and fewer pathogens disperse to them (Altizer et al. 2007, Gibson et al. 2010). Reduced exposure to pathogens, in turn, might lead to the evolution of reduced defense, making species that are rare at a large scale more susceptible to infection if subsequently exposed (Laine 2006). If regionally rare species are more susceptible they may also accumulate more pathogens around their roots and transmit these to other plants in their surroundings. Some of these ideas have been tested in animals (Altizer et al. 2007) or with plant foliar pathogens (Gibson et al. 2010) but the potential role of soil biota in determining range size, or other aspects of large-scale rarity, has never been considered.

The degree of specialization amongst soil biota has important consequences for understanding their effects on community structure and for predicting spill-over events (the transmission of pathogens/mutualists between plants), e.g., following range expansion or invasion (Power and Mitchell 2004). Aboveground pathogens and herbivores can show a phylogenetic signal in host range, meaning that closely related plants share more foliar pathogens (Gilbert and Webb 2007, Gilbert et al. 2012) or insect herbivores (Novotny and Basset 2005) than distantly related plants and spill-overs are more frequent between closely related hosts (Parker et al. 2015). Plant-soil feedbacks have been shown to be highly specific (Kulmatiski et al. 2008), but it remains unclear whether close relatives share more pathogens or mutualists than distant relatives. A few studies have tested whether feedback strength in general is phylogenetically conserved, i.e., they have tested for phylogenetic signal in the overall response of plant species to soil biota (Brandt et al. 2009, Anacker et al. 2014). Their results imply that more closely related plants respond more similarly to a given soil inoculum, and might therefore have similar levels of defense against, or tolerance to, soil pathogens. However, few plantsoil feedback studies have grown plants on soils previously cultured by many different plant species, which would be necessary to test for a relationship between plant relatedness and the probability of sharing soil pathogens or mutualists. If mutualists are moderately specific then plants would culture soil that benefits closely related species more than more distantly related ones and the opposite would occur if soil pathogens are moderately specific. If pathogens are either species specific or highly generalist then we would expect no relationship between phylogenetic distance and soil feedback effects. Of the few existing studies that tested for a relationship between phylogenetic distance and soil feedback strength, one showed that a subtropical tree cultured soil which had stronger negative effects on the growth of more closely related species (Liu et al. 2012), whereas another study found the opposite pattern using several Asteraceae species (Münzbergová and Surinová 2015). Fitzpatrick et al. (2017) found no effect of phylogenetic relatedness on soilfeedback strength when growing nine focal plant species on soils cultured by a large number of species, as did a metaanalysis (Mehrabi and Tuck 2014). These contrasting results mean it is unclear whether phylogenetic relatedness can predict plant soil feedback effects and thus if closely related plants interact positively or negatively with each other through their impacts on soil communities.

We present results from a multi-species soil feedback experiment, using 19 plant species from different habitats, which differ strongly in their rarity at large and local scales and in their phylogenetic relatedness to each other. Rarity and commonness at a large scale did not necessarily correspond with rarity and commonness at a local scale, as half of our plant species considered to be "rare at a large scale" usually reach high abundances at a local scale, and half of the species considered to be "common at a large scale" usually occur in low abundances locally (see Methods section). This design allowed us to test (1) whether plants that are regionally or locally rare generally suffer more from soil biota than species that are regionally or locally common, (2) whether locally or regionally rare species also accumulate more soil pathogens, and therefore whether soil trained by rare species has stronger negative effects on the growth of other species, and (3) whether plants grown on soil trained by close relatives grow worse than those grown on soil trained by distant relatives.

\section{Methods}

\section{Plant species}

To test whether rare species suffer from a stronger negative soil feedback than common species and whether there is a phylogenetic signal in the host range of soil organisms, we assessed the growth of 24 target plant species (herbs and grasses), differing in their degree of rarity or commonness at a large spatial scale, and also in their local abundance, on various soils differing in their phylogenetic relatedness to the target.

We used a crossed design with both regionally and locally rare plant species. For regional rarity, we compared two different metrics. We first classified the 24 species, and seven additional species which were used only for training soil (see below), as 'regionally common' or 'regionally rare' a priori. We ensured that the regionally rare and common species were paired, so that the pair were congenerics, or if not confamiliars (Appendix S1: Table S1). Secondly, we used the range size of the species in Switzerland (calculated as the number of $10 \times 10 \mathrm{~km}$ grid cells occupied by the species) as an additional measure of regional rarity. Range size of regionally rare species was significantly lower than range size for regionally common species $\left(F_{1,28}=43 ; P<0.0001\right.$; Appendix S1: Table S1). Unfortunately, a continuous measure of European range sizes for our plant species is not available yet. However, for a subset of our species (22 out of 31 species) for which European range size was available, Swiss and European range sizes were highly correlated (see Appendix S1: Text S1).

Our species also differed in their local rarity, as we wanted to test whether susceptibility to specialist soil organisms might determine their ability to build up large populations. 
Half of the regionally common and rare plants were therefore species that usually grow in larger groups or stands at the place where they occur (locally abundant), the other half were species that usually are scattered or only grow in small groups (locally scattered; Appendix S1: Table S1).

\section{Training of the soil}

In a first phase we used 31 species to train soils. In March 2012, we grew the 31 species individually in five $1.3 \mathrm{~L}$ pots filled with a mix of soil (20\% compost, $20 \%$ field soil from an agricultural area of the Swiss Plateau region, 20\% wood fiber, $40 \%$ peat). We refer to these 31 species as "soil species". We used more soil species than target species to ensure that each target species was grown on soils cultured by species with a wide range of phylogenetic distances from it (see Experimental design section and Fig. 1B). Pots were placed in a common garden in five blocks (Muri near Bern, Switzerland), and watered when needed. In October 2013 we harvested the soil from all soil species. We cut aboveground plant parts at soil level and freed the soil from roots by sieving (1 cm mesh). Soils of the five pots per species were pooled, homogenized and cold-stored for 5 weeks. Note that by using a standard soil mix for all species we are likely to have excluded specialist pathogens and mutualists occurring in each species' natural habitats. However, the response of our focal plants to these microbial communities might still give important insights into their overall susceptibility to generalist or moderate specialist soil microbes, which could potentially affect spread into new habitats. Also, it is possible that our experimental setup discriminated against certain soil organisms, particularly the soil sieving might be detrimental to soil nematodes. This would suggest that soil microbes are more likely to be responsible for the effects that we observe. It might also be that the trained soil of some plant species contains more root fragments than the soil of other plant species, if the thresholds when roots break differ between species. However, we do not think that this influences our results as it is unlikely that all regionally rare plant species have a higher or lower threshold for roots to break. Moreover, our use of rare and common plant species from the same plant genus, or at least plant family, makes such a bias unlikely.

\section{Experimental design}

We grew each of the 24 target species on six soils, each trained by a different species. Soils were selected so that they represented a wide range of phylogenetic distances between target and soil species. Specifically, each species grew on soil with a history of: the same species, a species of the same genus, a species of the same plant family, a species of a different plant family and a species of a different major Angiosperm lineage (i.e., eudicots versus monocots, Fig. 1B). All target plants were also grown in sterile soil (Fig. 1B), so that we could assess the total effect of the different soil communities on each target species. Rare species might cultivate different soil communities than common species, so we ensured that each target plant was grown on soils trained by approx equal numbers of regionally rare and regionally common species (red and black colours, Fig 1B; Appendix S1: Table S2), and also of locally rare and common species. Each target species $\times$ soil combination $(24$ target species $\times 6$ different soils) was replicated four times, resulting in 576 pots, which we arranged in four blocks in a greenhouse $\left(14^{\circ} \mathrm{C}\right.$, to $30^{\circ} \mathrm{C}$, a constant day length of $\left.14 \mathrm{~h}\right)$.

To produce the soils used to grow the target species, we used the trained soil to inoculate standard soil. This minimized differences in soil structure and nutrients between the various soils and ensured that we only tested the biotic component of the feedback (Brinkman et al. 2010). We first sterilized standard soil, i.e., a 1:1 mixture of sand and potting soil, by autoclaving. Then we thoroughly mixed 9 parts of standard soil with one part of trained soil. Each pot then received $1 \mathrm{~L}$ of the inoculated standard soil, or $1 \mathrm{~L}$ of uninoculated standard soil. We fertilized the pots twice with a liquid NPK fertilizer. We cannot fully rule out that differences between sterile and inoculated standard soil are due to differences in nutrients or allelochemicals, however, several studies have shown a limited effect of nutrients and allelochemicals in soil feedback experiments (Petermann et al. 2008, del Fabbro and Prati 2015) and by fertilising the pots it is likely that we removed any small differences in nutrient levels.

In December 2013 we sowed 10-40 seeds (depending on germination rates) of our target species into the pots containing the different soils, and thinned the emerging seedlings to one per pot. Five of our target species (Carex bicolor, Cyperus flavescens, Salvia pratensis, Daucus carota and Linaria alpina subsp. petrea) did not germinate in sufficient numbers and had to be excluded from the analysis, leaving us with 19 target species.

We harvested the biomass of each target plant between late April and June 2013. Species were harvested when they were at peak biomass or when most of their individuals were flowering. Plants were always harvested in pairs, so that the regionally rare and regionally common species from each pair were harvested at the same time (to not confound harvest date with regional rarity). We clipped aboveground biomass at soil level, washed the roots and dried and weighed the above-and belowground biomass.

\section{Phylogenetic relatedness}

We used a categorical measure of taxonomic distance (conspecific, congeneric, confamiliar, same lineage, different lineage) and a continuous measure of phylogenetic distance between soil and target species. For the latter we used a dated phylogeny of the European flora (Durka and Michalski 2012) to construct a phylogenetic tree of all plant species ( 31 species in total). We then used this to assess the phylogenetic relatedness between our 19 target species and each of the different soil species. We calculated phylogenetic distance (in million years) using the cophenetic function in R. Phylogenetic distance between conspecifics was coded as 0 . Models using the continuous measure of phylogenetic distance had lower AIC (better model fit) than the categorical measure of taxonomic distance, and we thus only present results of the former (see Appendix S1: Text S2 and Table S3 for results of the categorical measure).

\section{Statistical analysis}

We calculated the biomass response to the different soils for each target species using a log-response ratio, comparing 
growth on trained soils relative to sterile soil as: $\log$ (total biomass on soil with biota/total biomass on sterile soil). We refer to the log response ratio as soil feedback hereafter. A positive soil feedback would indicate a mutualistic net effect of soil biota (greater growth than on sterile soil), while a negative soil feedback would indicate a pathogenic net effect (lower growth than on sterile soil). The sterile soil comparison is most important because we want to look at the overall impact of soil biota, including generalist pathogens which could affect range expansion (Turnbull et al. 2010).

We calculated soil feedbacks for each target species using the mean biomass per target species and soil species across all four blocks ( 95 soil feedbacks, 19 target species $\times 5$ different soils). We used linear mixed effects models (lmer, package lme4 in R; R Core Team 2012). To assess whether (1) regionally or locally rare plant species suffered more from soil biota than regionally or locally common species, (2) whether they cultured soil communities with a stronger effect on other plants and (3) whether there was a phylogenetic signal in the host range of soil organisms, we fitted (1) regional and local rarity of the target species (see below), (2) regional and local rarity of the soil species (see below) and (3) phylogenetic distance (PD) as fixed factors. We also included all possible interactions with $\mathrm{PD}$ to test whether regionally or locally rare species are affected more strongly by more specialist soil organisms. Because soil-feedback strength might not linearly decrease with $\mathrm{PD}$ we also included the quadratic term $\mathrm{PD}^{2}$, and all possible interactions with $\mathrm{PD}^{2}$. We also fitted interactions between the regional rarity of soil and target species (and three way interactions with PD), to test if rare species are particularly sensitive to soil cultured by other rare species. However, we did not have enough power to also fit interactions between local and regional rarity or local rarity of soil and target species (see Table 1).

We included target species (19 levels) and soil species (31 levels) as crossed random terms and also tested models with different random slopes for phylogenetic distance for each target species (which yielded worse model fits, suggesting that target species do not differ substantially in their response to phylogenetic distance). To test which aspects of regional rarity affected plant soil-feedback strength, we used two different measures: a categorical variable based on IUCN status (status [regionally rare or common]: incorporating information on population size and trend as well as range size) or only range size (log transformed). We constructed four different models for the four possible combinations of regional rarity of soil or target species, each coded as status or range size. We compared the models using AIC: the model using status of target species and range size of soil species had AIC values 5 units lower than the second best model (status target and range size soil: $\mathrm{AIC}=211$; range size target and range size soil: $\mathrm{AIC}=217$; status target and status soil: $\mathrm{AIC}=228$; range size target and status soil: AIC = 232). We simplified the best model and derived significances using likelihood-ratio tests comparing models with and without the factor of interest.

\section{RESULTS}

Overall, the soil biota had a negative effect on total biomass produced by our target plant species (plants grown in
TABLE 1. Results of a linear mixed effect model testing for the effects of phylogenetic relatedness and regional and local plant rarity on plant biomass (using the log-response ratio of total plant biomass (relative to sterile soil) as dependent variable).

\begin{tabular}{|c|c|c|c|}
\hline Fixed factors & $\chi^{2}$ & df & $P$-Value \\
\hline Phylogenetic distance (PD) & 5.45 & 1 & $0.02 \dagger$ \\
\hline Regional rarity target species & 7.2 & 1 & $0.007 \dagger$ \\
\hline Regional rarity soil species & 4.45 & & $0.03 \dagger$ \\
\hline Local abundance target species & 2 & 1 & 0.16 \\
\hline Local abundance soil species & 0.9 & 1 & 0.34 \\
\hline $\mathrm{PD}^{2}$ & 3.6 & 1 & 0.06 \\
\hline $\mathrm{PD} \times$ regional rarity target species & 0.004 & 1 & 0.95 \\
\hline $\mathrm{PD} \times$ regional rarity soil species & 4.8 & 1 & 0.03 \\
\hline PD $\times$ Local abundance target species & 0.45 & 1 & 0.501 \\
\hline $\mathrm{PD} \times$ Local abundance soil species & 0.51 & 1 & 0.47 \\
\hline $\begin{array}{l}\text { Regional rarity target } \\
\text { species } \times \text { regional rarity soil species }\end{array}$ & 4.9 & 1 & 0.03 \\
\hline $\mathrm{PD}^{2} \times$ regional rarity target species & 2.7 & 1 & 0.1 \\
\hline $\mathrm{PD}^{2} \times$ local abundance target species & 0.106 & 1 & 0.74 \\
\hline $\mathrm{PD}^{2} \times$ local abundance soil species & 0.68 & 1 & 0.41 \\
\hline $\mathrm{PD}^{2} \times$ regional rarity soil species & 0.91 & 1 & 0.34 \\
\hline $\begin{array}{l}\mathrm{PD} \times \text { regional rarity target } \\
\text { species } \times \text { regional rarity soil species }\end{array}$ & 2.87 & 1 & 0.09 \\
\hline $\begin{array}{l}\mathrm{PD}^{2} \times \text { regional rarity target } \\
\text { species } \times \text { regional rarity soil species }\end{array}$ & 0.63 & 1 & 0.43 \\
\hline Random factors & Variance & SD & \\
\hline Target species & 0.179 & 0.424 & \\
\hline Soil species & 0.054 & 0.233 & \\
\hline
\end{tabular}

Notes: Significances were obtained by stepwise deletion of nonsignificant terms and comparing the resulting model to the previous one using log likelihood-ratio tests. This resulted in a minimal model containing only significant terms. We kept random factors in the model and present their variances. Note that regional rarity of the target species was coded as a categorical variable (IUCN status: regionally rare or regionally common), and regional rarity of the soil species as the range size of the species in Switzerland. Numbers in bold indicate statistical significance.

$\dagger$ To obtain $\chi^{2}$ and $P$-values of main effects we excluded all higher-level interactions and compared this model with models omitting the factor of interest.

sterile soil produced more biomass than plants in soil with biota, estimate for the soil feedbacks from an intercept only model using target species and soil species as random terms $=-1.11,95 \%$ CI: $[-1.42,-0.83])$. However, the growth of regionally rare plant species was reduced more than twice as much by soil biota, in comparison with the growth of regionally common species (Table 1, Fig. 2A) indicating that regionally rare species are generally more susceptible to soil biota or benefit less from mutualists. The negative effect of soil biota on regionally rare target plant species was particularly strong when the soil was trained by another regionally rare species (significant interaction of target status $\times$ soil species range size, Table 1, Fig. 2B). In contrast, regionally common target species grew only slightly worse in soil trained by regionally rare species than in soil trained by regionally common species. This might indicate that regionally rarer species also accumulated more pathogens or harboured fewer mutualists than regionally common species. Plant species that occur locally at low abundances did not differ in their response to soil biota, nor did their trained soil have different effects on other plant species, compared to species that are locally abundant (Table 1), providing no evidence that local abundance is driven by soil microbes in our experiment. 
A

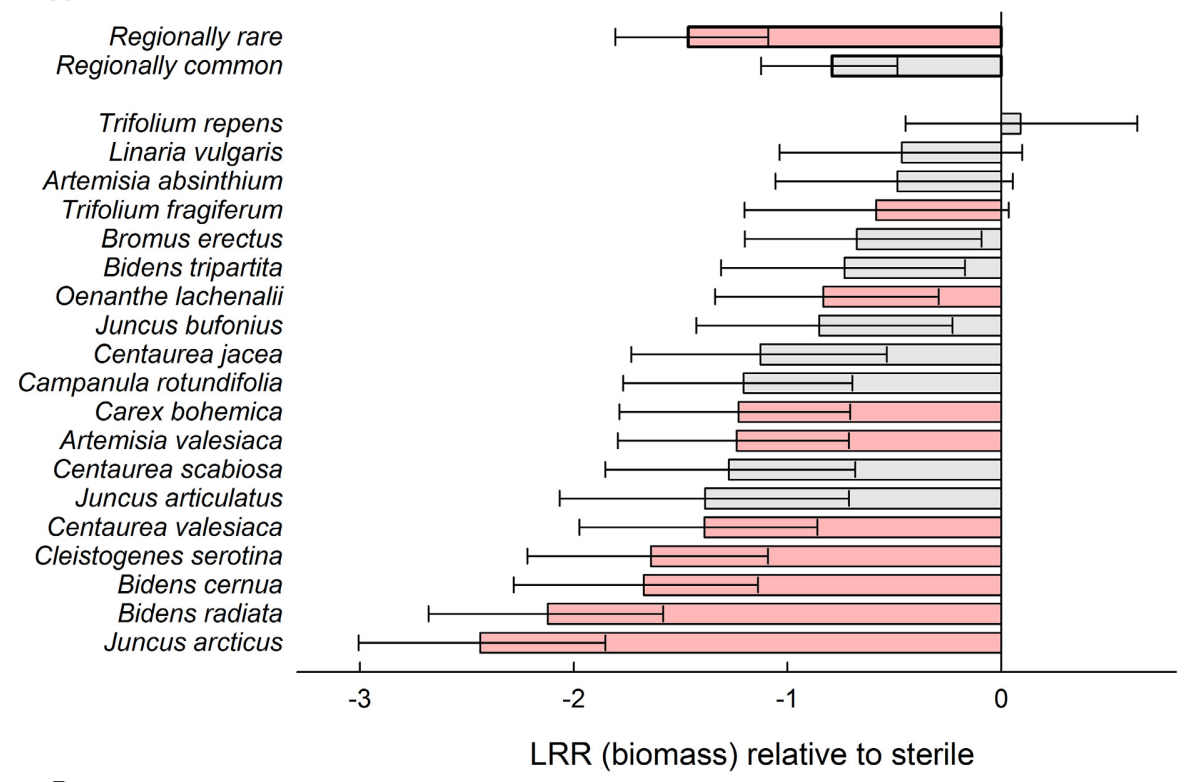

B

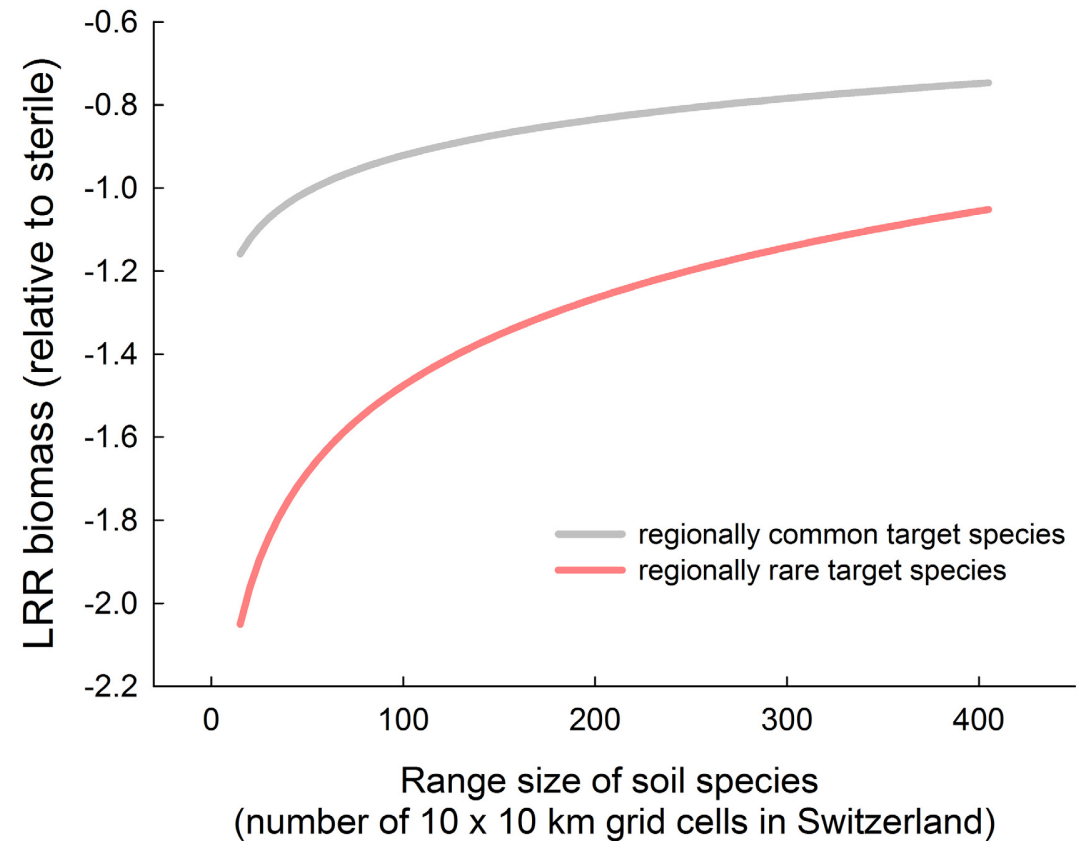

FIG. 2. (A) Overall effects of soil biota on the total biomass of regionally common (grey colors) and regionally rare and endangered (red colors) target plant species. Shown are soil feedbacks (log-response ratios, total biomass on trained soil relative to total biomass on sterile soil) and confidence intervals. Note that overlapping confidence intervals (regionally rare, regionally common) do not imply lack of statistical significance. (B) Effects of soil biota (shown as the log-response ratio of total biomass on trained soil relative to total biomass on sterile soil) on regionally common and regionally rare target plant species in relation to the range size of the soil species. Regionally rare target species suffered more from soil biota of small ranged-species whereas regionally common target species grew almost equally well in soil trained by species of small and large ranges.

Across all plant species, soil biota trained by closely related species had a more negative effect on subsequent growth than soil biota trained by more distantly related species (Table 1 , Fig. 3A). The effect of phylogenetic distance was linear (quadratic term was not significant, Table 1). However, the strength of the phylogenetic distance effect depended on the regional rarity of the species that trained the soil (significant phylogenetic distance $\times$ range size of soil species interaction). There was a strong effect of phylogenetic distance when soil had been trained by species that are rare at a large scale but only a weak effect when soil had been trained by regionally common species (Table 1, Fig. 3B). This suggests that species that are regionally rare accumulated more moderately specific soil pathogens than regionally common plants. Local abundance did not affect the strength of the phylogenetic distance effect (no PD $\times$ local rarity interaction, Table 1 ), which indicates that locally rare species did not suffer more from specialist soil microbes in our experiment. 

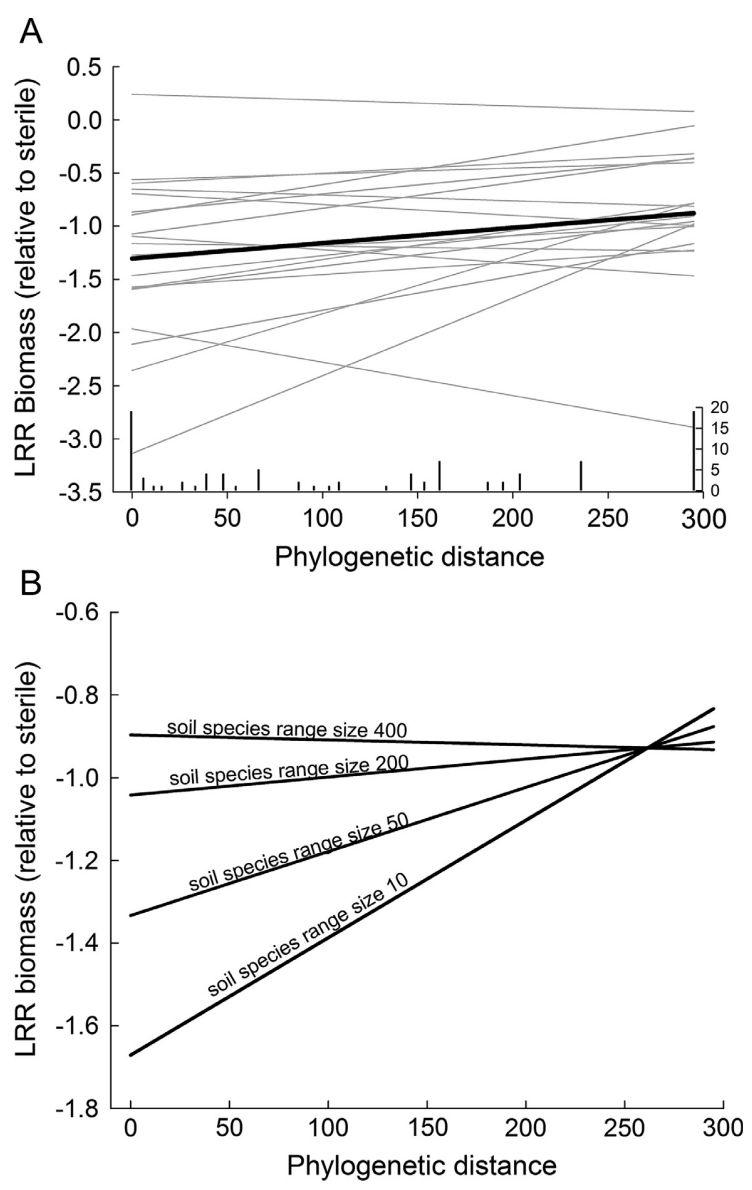

FIG. 3. Effects of phylogenetic distance (million years before present) on (A) the strength of soil feedback and (B) the strength of the soil feedback in relation to regional rarity (range size) of the soil species. In (A) individual lines for each target plant species on the effects of phylogenetic distance of the soil plant species (grey lines), and the fitted overall effect of phylogenetic distance (black line) on soil feedback strength are shown. The number of plant species at certain levels of phylogenetic distance are visualized at the bottom of the graph with a legend at the lower right. In (B) the strength of the effect of phylogenetic distance depended on the regional rarity of the species that trained the soil (significant phylogenetic distance $\times$ soil species range size interaction, Table 1). Shown are fitted slopes for soil species with a range size of 10, 50, 200 and 400 cells (calculated as the number of $10 \times 10 \mathrm{~km}$ grid cells occupied by a given species in Switzerland). The negative soil effect of closely related species was strongest when the soil was trained by regionally rare plant species.

Other studies have shown that certain clades in the phylogeny show stronger or weaker responses to soil biota (phylogenetic signal in response to soil biota, Anacker et al. 2014). However, we found no evidence for this in our dataset (Appendix S1: Text S3, Table S4).

\section{Discussion}

Plant species that are rare at a large scale suffer more from soil biota and accumulate more pathogens than common ones

Threatened plants were more susceptible to soil biota than common species (Fig. 2A), indicating that interactions with soil biota might explain large-scale patterns of rarity and commonness. Different aspects of regional rarity were important: both the categorical measure of large-scale rarity, based on IUCN status, and range size affected the response to soil communities. This suggests that species with fragmented and isolated populations, and those with small ranges, are most susceptible to soil organisms. Species that were locally rare were not necessarily regionally rare and it is likely that the drivers of rarity differ between these scales (Rabinowitz 1981). In particular, susceptibility to more generalist soil pathogens might restrict ranges (Turnbull et al. 2010), while at local scales, an increased susceptibility to specialist pathogens might cause increased negative frequency dependence which keeps population sizes small (Yenni et al. 2012, Fig. 1A). Several studies have found that locally rare plants experience more negative plant-soil feedback (Klironomos 2002, Mangan et al. 2010, MacDougall et al. 2011, McCarthyNeumann and Ibáñez 2012, Rutten et al. 2016, but see Reinhart 2012, Maron et al. 2016). In our experiment we found no evidence that plants with low local abundances suffered more from soil biota, perhaps because we used species occurring in different communities and therefore could not use local soil sampled from their natural habitats, meaning the experiment lacked the species specific pathogens causing increased negative frequency dependence in rare species. However, our experiment was well suited to identify a relationship between rarity at a large scale and overall susceptibility to soil organisms. The fact that species that are rare at a large scale suffered more than twice as much from soil biota than common plant species, indicates that soil biota could be an important driver of large-scale rarity.

Several studies have aimed to identify traits that predispose species to become regionally common or rare (Murray et al. 2002, Dawson et al. 2012), but biotic interactions have rarely been considered (but see Landa and Rabinowitz 1983). Our results suggest that plant-soil feedbacks could be a driver of regional rarity in endangered plants, and conversely that the ability to tolerate or resist detrimental soil organisms, or to benefit from mutualistic ones, might allow species to become widespread and common. Interestingly, regionally rare plants not only suffered more from soil biota (or benefited less) than common species, their soils also had stronger negative effects on the growth of other plant species (Fig. 2B). Regionally rare species therefore seem to accumulate detrimental soil biota at higher rates than regionally common species and to be generally more susceptible to soil pathogens. It might also be that rare species are less able to benefit from mutualists and/or accumulate beneficial microbes to a lower extent than common species. However, soil pathogens are generally considered to be the main agents of soil feedbacks (Packer and Clay 2000, McCarthy-Neumann and Ibáñez 2012), and the fact that we mainly found negative soil effects suggests a stronger role for pathogens than mutualists.

Regionally rare species might suffer more from soil biota because they benefit less from mutualists, because they are less tolerant of pathogens or they are less defended against pathogens. The most likely explanation for why soils trained by regionally rare plant species had a more negative effect on subsequent plant growth, is that rare species accumulated more pathogens due to lower defenses. But why should rarity at a large scale be related to lower defenses against soil pathogens? Species with lower defenses might be unable to spread 
into new habitats and might be at increased risk of extinction, making them regionally rare (Smith et al. 2006). Alternatively, a restricted range size and isolated populations might have resulted in the evolution of lower defenses against pathogens. Small ranged species might have been exposed to fewer pathogens in their evolutionary history (Feeny 1976), and species with fragmented populations may have reduced genetic diversity due to drift and inbreeding and may have lost resistance traits (Spielman et al. 2004). Moreover, regionally rare species commonly occur in isolated populations and may have lower pathogen loads because extinction rates are higher, and recolonization rates lower, for their pathogen populations (Lienert and Fischer 2003, Altizer et al. 2007). This means rare plants may have experienced selection against pathogen defense, making them highly susceptible if subsequently exposed (Laine 2006). We cannot disentangle whether the higher susceptibility of regionally rare plant species to soil biota is the cause or the consequence of large-scale patterns of plant rarity. Future studies manipulating different aspects of rarity orthogonally, i.e. including small and large (declining and stable) populations of plant species differing in range size, could test whether a higher susceptibility to soil pathogens is a result of isolation and fragmentation (and reduced genetic variability), or whether inherent species traits related to resistance define the current distribution and abundance of plant species.

In our study, all plants were grown in commercial potting soil, which most likely harbored a reduced diversity and a different composition of soil biota than soils from the species' natural habitats. In particular, specialist mutualists and pathogens naturally occurring with our species might have been lacking. Regionally rare species might associate with rare mutualist microbes in their natural habitats (as shown for orchids, Phillips et al. 2011), and these could offset some of the negative pathogen effects. It is therefore possible that regionally rare species may have experienced more negative feedback in our experiment than they would in their natural habitats. As in other multi-species, soil feedback experiments (Mangan et al. 2010, Maron et al. 2016), we have no information on the specific soil organisms responsible and we cannot tell whether certain species accumulated fungal pathogens, detrimental soil bacteria or mutualists at higher or lower rates, or whether soil communities differed between common and rare plant species. Also, the sieving of the soil might have discriminated against certain plant enemies, such as soil nematodes. However, despite these limitations and, although our results might not entirely reflect the effects of soil biota on plants in their natural habitats, they do suggest that regionally rare species suffer more from widely distributed soil biota than common species. This supports results showing that range expanding species suffer less from plant-soil feedbacks (Engelkes et al. 2008, Morrien and van der Putten 2013). Species which are already regionally rare might therefore have even greater difficulties in shifting their ranges to track a suitable climate, and this might further raise their risk of extinction in the near future.

\section{Stronger negative feedbacks in soil of closely related plant species}

It has long been expected that more closely related species should compete more intensely (Darwin 1859) but the evidence for this has been mixed (Cahill et al. 2008) and recently phylogenetic relatedness has been shown to be a poor proxy for niche differences between species (Godoy et al. 2014, Gerhold et al. 2015). Here we provide evidence that the degree of phylogenetic relatedness may instead predict the degree of apparent competition (Holt 1977), mediated by soil organisms, between species. Although soil organisms can strongly affect plant fitness (Burdon 1987), they have mainly been ignored in studies relating interactions between plant species to phylogeny. Our results suggest that spill-overs of detrimental soil organisms are more likely between closely related species (Fig. 3A). Increased sharing of mutualists between distantly related species could also partially explain this pattern as mutualistic interactions with mycorrhizal fungi have been suggested to be highly generalist (Smith and Read 2008), or even more dissimilar between closely related plants (Reinhart and Anacker 2014). It is plausible that both increased pathogen sharing between close relatives, and increased mutualist sharing between distant relatives, causes a phylogenetic signal in plant-soil feedback. Previous studies testing for this pattern showed contrasting results (Liu et al. 2012, Mehrabi and Tuck 2015, Münzbergová and Šurinová 2015, Fitzpatrick et al. 2017). Our approach of growing each plant on soils cultured by heterospecifics varying in phylogenetic distance to the target, may have more power to detect a phylogenetic signal in host range and studies on leaf pathogens and insect herbivores have used a similar approach to demonstrate phylogenetic signal in host range (Novotny and Basset 2005, Gilbert and Webb 2007). Plant enemies and mutualists might drive indirect competitive interactions between their hosts and could prevent closely related plants from co-occurring (Parker et al. 2015) or co-dominating communities (Allan et al. 2013) (phylogenetic overdispersion). Phylogenetic relationships may therefore be useful in predicting the sharing of natural enemies (or mutualist) between plants.

Interestingly, the negative feedback effect on growth was stronger when the soil had been trained by small ranged species (Fig. 3B). This suggests that regionally rare plants accumulate a more specialist soil biota, although the biota seems not to be species specific and rather moderately specific as it is shared between close relatives. This might simply be due to a sampling effect: rare species generally accumulate a larger number of soil pathogens (Fig 2), meaning they also accumulate more moderately specific soil pathogens. Alternatively, rare species might be less defended against moderately specialist soil pathogens. Although different evolutionary responses of plants to generalist and specialist pathogens were hypothesized (Jarosz and Davelos 1995), we know very little about variation in plant defenses against soil pathogens and whether they respond differently to soil microbes differing in their degree of specialization.

Our findings that regionally common plants are less affected by soil organisms in general, and by moderately specialist soil organisms in particular, agrees with findings from invasion biology. It has been shown that some invasive species are less responsive to soil enemies and can profit more from mutualists (Klironomos 2002, Reinhart and Callaway 2006, Engelkes et al. 2008, but see e.g., Callaway et al. 2008 showing inhibition of mycorrhizal fungi required by natives). This might be due to release from specialist enemies (enemy 
release hypothesis), however this would not explain how invasive species can spread into areas containing closely related natives, if spill-overs occur between closely related plants. Therefore, it is more likely that commonness (in the native or invasive range) is related to a higher resistance against generalist and moderately specialist enemies.

\section{Conclusion}

With our multi-species experiment we showed that regionally rare plant species not only suffer more from soil biota but also appear to accumulate more pathogens, and more specialist pathogens, than regionally common species. Moreover, our results strongly suggest a phylogenetic signal in the host range of detrimental soil biota, indicating that soil pathogens are neither entirely species-specific nor entirely generalist, but can infest closely related plant species. Phylogenetic relatedness therefore seems to remain relevant for predicting sharing of natural enemies between plant species and soil pathogens may have played a role in driving previously observed patterns of phylogenetic overdispersion. Soil biota which are entirely species specific would not be able to restrict range size, although there is evidence that they are important for driving local rarity. Our results suggest that it is moderately specialist pathogens (shared between close relatives) that are responsible for restricting species ranges. This is the first evidence that soil organisms could drive rarity and commonness of plant species at large scales and suggests rare species may struggle to shift their ranges in a changing climate. Moreover, conservation biologists may increasingly have to consider the role of soil organisms in restricting the range and population size of rare and endangered species.

\section{ACKNOWLEDGEMENTS}

We thank Michael Bartoš and Karl Kasper for help in the greenhouse, Santiago Soliveres and three reviewers for helpful comments on the manuscript.

\section{Literature Cited}

Allan, E., T. Jenkins, A. J. F. Fergus, C. Roscher, M. Fischer, J. S Petermann, W. W. Weisser, and B. Schmid. 2013. Experimental plant communities develop phylogenetically overdispersed abundance distributions during assembly. Ecology 94:465-477.

Altizer, S., C. L. Nunn, and P. Lindenfors. 2007. Do threatened hosts have fewer parasites? A comparative study in primates. Journal of Animal Ecology 76:304-314.

Anacker, B. L., J. N. Klironomos, H. Maherali, K. O. Reinhart, and S. Y. Strauss. 2014. Phylogenetic conservatism in plant-soil feedback and its implications for plant abundance. Ecology Letters 17:1613-1621.

Bever, D., S. A. Mangan, and H. M. Alexander. 2015. Maintenance of plant species diversity by pathogens. Annual Review of Ecology, Evolution, and Systematics 46:305-325.

Boulangeat, I., D. Gravel, and W. Thuiller. 2012. Accounting for dispersal and biotic interactions to disentangle the drivers of species distributions and their abundances. Ecology Letters 15:584-593.

Brandt, A. J., E. W. Seabloom, and P. R. Hosseini. 2009. Phylogeny and provenance affect plant-soil feedbacks in invaded California grasslands. Ecology 90:1063-1072.

Brinkman, E. P., W. H. van der Putten, E. J. Bakker, and K. J. Verhoeven. 2010. Plant-soil feedback: experimental approaches, statistical analyses and ecological interpretations. Journal of Ecology 98:1063-1073.
Brown, J. H. 1984. On the relationship between abundance and distribution of species. American Naturalist 124:255-279.

Burdon, J. J. 1987. Diseases and plant population biology. Cambridge University Press, Cambridge, UK.

Cahill, J. F., S. W. Kembel, E. G. Lamb, and P. A. Keddy. 2008. Does phylogenetic relatedness influence the strength of competition among vascular plants? Perspectives in Plant Ecology, Evolution and Systematics 10:41-50.

Callaway, R. M., G. Thelen, A. Rodriguez, and W. E. Holben. 2004. Soil biota and exotic plant invasion. Nature 427:731-733.

Callaway, R. M., D. Cipollini, K. Barto, G. C. Thelen, S. G. Hallett, D. Prati, K. Stinson, and J. Klironomos. 2008. Novel weapons: invasive plant suppresses fungal mutualists in America but not in its native Europe. Ecology 89:1043-1055.

Darwin, C. 1859. The origin of species by means of natural selection. Murray, London, UK.

Dawson, W., M. Fischer, and M. van Kleunen. 2012. Common and rare plant species respond differently to fertilisation and competition, whether they are alien or native. Ecology Letters 15:873-880.

del Fabbro, C., and D. Prati. 2015. Invasive plant species do not create more negative soil conditions for other plants than natives. Perspectives in Plant Ecology Evolution and Systematics 17:87-95.

Durka, W., and S. G. Michalski. 2012. Daphne: a dated phylogeny of a large European flora for phylogenetically informed ecological analyses. Ecology 93:2297.

Engelkes, T., E. Morrien, K. J. F. Verhoeven, T. M. Bezemer, A. Biere, J. A. Harvey, L. M. McIntyre, W. L. M. Tamis, and W. H. van der Putten. 2008. Successful range-expanding plants experience less above-ground and below-ground enemy impact. Nature 456:946-948.

Feeny, P. 1976. Plant apparency and chemical defense in J. W. Wallace and R. L. Mansell, editors. Recent advances in phytochemistry. Plenum Press, New York, New York, USA.

Fitzpatrick, C. R., L. Gehant, P. M. Kotanen, and M. T. Johnson. 2017. Phylogenetic relatedness, phenotypic similarity and plantsoil feedbacks. Journal of Ecology 105:786-800.

Gaston, K. J. 1994. Rarity. Chapman and Hall, London, UK.

Gerhold, P., J. F. Cahill, M. Winter, I. V. Bartish, and A. Prinzing. 2015. Phylogenetic patterns are not proxies of community assembly mechanisms (they are far better). Functional Ecology 29:600-614.

Gibson, A. K., J. I. Mena-Ali, and M. E. Hood. 2010. Loss of pathogens in threatened plant species. Oikos 119:1919-1928.

Gilbert, G. S., and C. O. Webb. 2007. Phylogenetic signal in plant pathogen-host range. Proceeding of the National Academy of Sciences 104:4979-4983.

Gilbert, G. S., R. Magarey, K. Suiter, and C. O. Webb. 2012. Evolutionary tools for phytosanitary risk analysis: phylogenetic signal as a predictor of host range of plant pests and pathogens. Evolutionary Applications 5:869-878.

Godoy, O., N. J. B. Kraft, and J. M. Levine. 2014. Phylogenetic relatedness and the determinants of competitive outcomes. Ecology Letters 17:836-844.

Hanski, I., J. Kouki, and A. Halkka. 1993. Three explanations of the positive relationship between distribution and abundance of species. Pages 108-116 in R. E. Ricklefs and D. Schluter, editors. Species diversity in ecological communities: historical and geographical perspectives. University of Chicago Press, Chicago, Illinois, USA.

Holt, R. D. 1977. Predation, apparent competition, and the structure of prey communities. Theoretical Population Biology $12: 197-229$

Jarosz, A. M., and A. L. Davelos. 1995. Effects of disease in wild plant-populations and the evolution of pathogen aggressiveness. New Phytologist 129:371-387.

Klironomos, J. N. 2002. Feedback with soil biota contributes to plant rarity and invasiveness in communities. Nature 417:67-70.

Kulmatiski, A., K. H. Beard, J. R. Stevens, and S. M. Cobbold. 2008. Plant-soil feedbacks: a meta-analytical review. Ecology Letters 11:980-992. 
Laine, A.-L. 2006. Evolution of host resistance: looking for coevolutionary hotspots at small spatial scales. Proceedings of the Royal Society B 273:267-273.

Landa, K., and D. Rabinowitz. 1983. Relative preference of Arphia sulphurea (Orthoptera: Acrididae) for sparse and common prairie grasses. Ecology 64:392-395.

Lienert, J., and M. Fischer. 2003. Habitat fragmentation affects the common wetland specialist Primula farinosa in north-east Switzerland. Journal of Ecology 91:578-599.

Liu, X., M. Liang, R. S. Etienne, Y. Wang, C. Staehelin, and S. Yu. 2012. Experimental evidence for a phylogenetic Janzen-Connell effect in a subtropical forest. Ecology Letters 15:111-118.

MacDougall, A. S., M. C. Rillig, and J. N. Klironomos. 2011. Weak conspecific feedbacks and exotic dominance in a species-rich savannah. Proceedings of the Royal Society B 278: 2939-2945.

Mangan, S. A., S. A. Schnitzer, E. A. Herre, K. M. L. Mack, M. C. Valencia, E. I. Sanchez, and J. D. Bever. 2010. Negative plant-soil feedback predicts tree-species relative abundance in a tropical forest. Nature 466:752-755.

Maron, J. L., A. Laney Smith, Y. K. Ortega, D. E. Pearson, and R. M. Callaway. 2016. Negative plant-soil feedbacks increase with plant abundance, and are unchanged by competition. Ecology 97:2055-2063.

McCarthy-Neumann, S., and I. Ibáñez. 2012. Tree range expansion may be enhanced by escape from negative plant-soil feedbacks. Ecology 93:2637-2649.

Mehrabi, Z., and S. L. Tuck. 2015. Relatedness is a poor predictor of negative plant-soil feedbacks. New Phytologist 3:1071-1075.

Morrien, E., and W. H. van der Putten. 2013. Soil microbial community structure of range-expanding plant species differes from co-occuring natives. Journal of Ecology 101:1093-1102.

Münzbergová, Z., and M. Šurinová. 2015. The importance of species phylogenetic relationships and species traits for the intensity of plant-soil feedback. Ecosphere 6:1-16.

Murray, B. R., P. H. Thrall, A. M. Gill, and A. B. Nicotra. 2002. How plant life-history and ecological traits relate to species rarity and commonness at varying spatial scales. Austral Ecology 27:291-310.

Novotny, V., and Y. Basset. 2005. Host specificity of insect herbivores in tropical forests. Proceedings of the Royal Society B 272:1083-1090.

Packer, A., and K. Clay. 2000. Soil pathogens and spatial patterns of seedling mortality in a temperate tree. Nature 404:278-281.
Parker, I. M., M. Saunders, M. Bontrager, A. P. Weitz, R. Hendricks, R. Magarey, K. Suiter, and G. S. Gilbert. 2015. Phylogenetic structure and host abundance drive disease pressure in communities. Nature 520:542-544.

Petermann, J. S., A. J. F. Fergus, L. A. Turnbull, and B. Schmid. 2008. Janzen-Connell effects are widespread and strong enough to maintain diversity in grasslands. Ecology 89:2399-2406.

Phillips, R. D., M. D. Barrett, K. W. Dixon, and S. D. Hopper. 2011. Do mycorrhizal symbioses cause rarity in orchids? Journal of Ecology 9:858-869.

Power, A. G., and C. E. Mitchell. 2004. Pathogen spillover in disease epidemics. American Naturalist 164:79-89.

R Core Team. 2012. R: a language and environment for statistical computing. R Foundation for Statistical Computing, Vienna, Austria.

Rabinowitz, D. 1981. Seven forms of rarity. Pages 205-217 in H. Synge, editor. The biological aspects of rare plant conservation. John Wiley, Chichester, UK.

Reinhart, K. O. 2012. The organization of plant communities: negative plant-soil feedbacks and semiarid grasslands. Ecology 93:2377-2385.

Reinhart, K. O., and B. L. Anacker. 2014. More closely related plants have more distinct mycorrhoyal communities. AoB Plants 6:plu051. https://doi.org/10.1093/aobpla/plu051

Reinhart, K. O., and R. M. Callaway. 2006. Soil biota and invasive plants. New Phytologist 170:445-457.

Rutten, G., D. Prati, A. Hemp, and M. Fischer. 2016. Plant-soil feedback in East-African savanna trees. Ecology 97:294-301.

Slatyer, R. A., M. Hirst, and J. P. Sexton. 2013. Niche breadth predicts geographical range size: a general ecological pattern. Ecology Letters 16:1104-1114.

Smith, S. E., and D. J. Read. 2008. Mycorrhizal symbiosis. Academic Press, London.

Smith, K. F., D. F. Sax, and K. D. Lafferty. 2006. Evidence for the role of infectious disease in species extinction and endangerment. Conservation Biology 20:1349-1357.

Spielman, D., B. Brook, D. Briscoe, and R. Frankham. 2004. Does inbreeding and loss of genetic diversity decrease disease resistance? Conservation Genetics 5:439-448.

Turnbull, L. A., J. M. Levine, A. J. F. Fergus, and J. S. Petermann. 2010. Species diversity reduces invasion success in pathogenregulated communities. Oikos 119:1040-1046.

Yenni, G., P. B. Adler, S. Ernest, and K. Morgan. 2012. Strong selflimitation promotes the persistence of rare species. Ecology 93: 456-461.

\section{SUPPORTING INFORMATION}

Additional supporting information may be found in the online version of this article at http://onlinelibrary.wiley.com/doi/10.1002/ecy. 2145/suppinfo 